\title{
Iron-doped Nickel Oxide Nanoparticles Synthesis and Analyzing Different Properties
}

Manar Saleh Alshatwi*, Huda Abdulrahman Alburaih, Shahad Salem Alghamdi, Danah Abdullah Alfadhil, Joud Awadh Alshehri, Farah Abdullah Aljamaan

Faculty of Science, Department of physics, Princess Nourah Bint Abdulrahman University, Riyadh, 13415, Saudi Arabia

\begin{tabular}{l} 
A R T I C L E I N F O \\
\hline Article history: \\
Received: 06 October, 2020 \\
Accepted: 30 January, 2021 \\
Online: 28 February, 2021 \\
\hline Keywords: \\
Fe doped NiO \\
Optical studies \\
Nickel oxide nanoparticles \\
Optica bandgap \\
Morphological analysis
\end{tabular}

A B S T R A C T
This is a report describing the impact of calcination on the morphological and optical
properties of nanoparticles Iron doped-nickel oxide. By synthetic precipitation, the
technique makes use of it. Three samples have been calcined in different temperatures and
were characterized by X-ray diffraction (XRD), Fourier transforms infrared spectroscopy
(FTIR), UV spectroscopy, and scanning electron microscopy (SEM), energy dispersive X-
Ray (EDX). The study showed that the increase in the temperature enhances the structural
and optical properties of the samples, and makes the samples take a more crystalline
structure. It is also shown that there has been an expansion of the volume of the samples,
making the samples having a small bandgap. UV-Visible absorption spectra of Iron doped-
nickel oxide nitrate shows a peak of absorption between 350 to 400 nm. The bandgap value
is calculated to be 1.86 eV at a calcination temperature of $350^{\circ} C$. The required structural
and optical properties of Iron doped-nickel oxide nanoparticles make it a promising material
for optoelectronic applications.

The XRD pattern of NiO NPs exhibits a face-centered cubic (FCC) crystalline structure [10]. The UV-IR spectrum of biosynthesized $\mathrm{NiO}$ Nanoparticles showed optical properties well-defined at $321 \mathrm{~nm}$ and its exhibited optical band gap is (3.83$3.18 \mathrm{eV}$ ) [13-16]. Furthermore, in previous studies, nanoparticles of $\mathrm{NiO}$ with different concentrations and calcination temperatures of Iron have been investigated, and it's found that the properties of $\mathrm{NiO} \mathrm{NPs}$ enhance with the addition of $\mathrm{Fe}$ and give excellent optical, structural, and magnetic properties. Therefore, this material can be a promising material when used in different applications such as optoelectronics, sensors, and batteries due its desired structural, optical, and magnetic properties. [8, 17, 18, 19, 20, 21, 22].

\section{Experimental}

\subsection{Materials}

The materials used in this research are: Nickel Nitride $\mathrm{Ni}$ $\left(\mathrm{NO}_{3}\right)_{2}$, Iron nitride $\left(\mathrm{Fe}_{2} \mathrm{~N}\right)$, Citric Acid $\left(\mathrm{C}_{6} \mathrm{H}_{8} \mathrm{O}_{7}\right)$, and Ammonia hydrate $\left(\mathrm{H}_{6} \mathrm{NO}\right)$.Deionized water was used in all the experimental procedures.

\subsection{Preparation of Iron doped $\mathrm{NiO}$ nanoparticles}

In this research, NPs of Iron doped $\mathrm{NiO}$ samples have been prepared by dissolving $13.81 \mathrm{~g}$ of Nickel Nitrate $\mathrm{Ni}\left(\mathrm{NO}_{3}\right)_{2}$ and $1.01 \mathrm{~g}$ Iron nitrate $\mathrm{Fe}\left(\mathrm{NO}_{3}\right)_{3}$ into an aqueous solution of $50 \mathrm{ml}$ distilled water under medium stirring speed and temperature of 50 
$\mathrm{C}^{\circ}$. After $15 \mathrm{~min}, 1 \mathrm{~g}$ of citric acid was added to the solution and kept stirring for another 15 minutes. Hereafter, Ammonium Hydrate (Liquid Ammonia) was added drop by drop, and precipitate started to appear until the mixture turned into a thick gel. Eventually, the temperature was raised to obtain a completely dry sample, which resulted in 5\% Fe doped $\mathrm{NiO}$ nanoparticles. The dried samples were ground into a powder. In the end, the samples were placed in a muffle furnace at different temperatures ranging at $(300,350,420){ }^{\circ} \mathrm{C}$ for 2 hours.

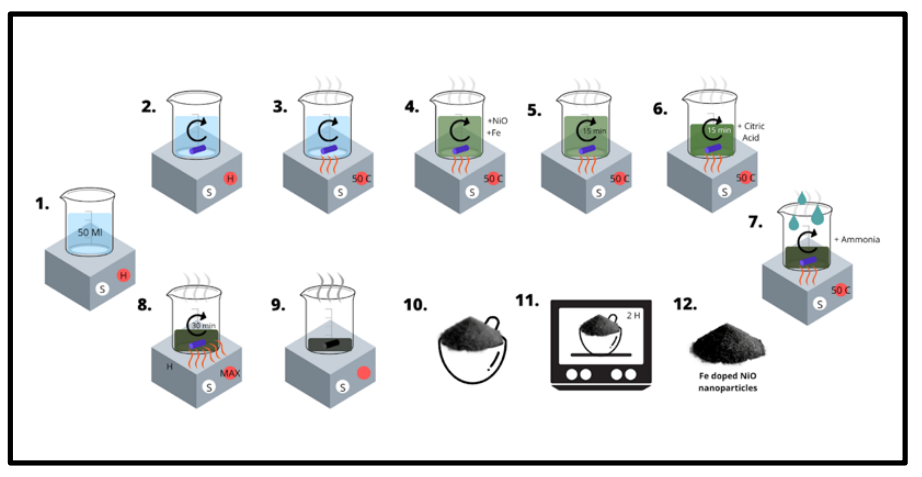

Figure 1: Iron-NiO Nanoparticles preparation method

\subsection{Measurements of microstructure and performance}

This work aims to study the impact of calcination temperatures at 300,350 , and $420^{\circ} \mathrm{C}$ on the structural and optical properties of Iron doped $\mathrm{NiO}$ samples. The structural properties of purity and crystalline $\mathrm{Fe}$ doped $\mathrm{NiO}$ were characterized by XRD measurements using Philips diffractometer with an accelerating voltage of $\left(\lambda=1.54^{\circ} \mathrm{A}\right)$ with $\mathrm{CuK} \alpha$ radiation. The morphological studies done by using a scanning electron microscope (SEM) have been carried out. equipped with EDAX to record the composition analysis (JEOL Model with an accelerating voltage of $30 \mathrm{kV}$ ). The optical properties of the samples were calculated with the SHIMADZU double beam UVvisible spectrophotometer. Finally, Thermal analysis was carried out by Perkin-Elmer Fourier transform-infrared spectroscopy (FTIR) over the range of $590-4000 \mathrm{~cm}^{-1}$.

\section{Result}

\subsection{XRD Analysis}

The structures of Iron-doped $\mathrm{NiO}$ nanoparticles calcined at $300,350,420{ }^{\circ} \mathrm{C}$ were analyzed using XRD and are represented in Fig.2. peaks of diffraction have been found near to $37.3^{\circ}, 43.1^{\circ}$, $62.90^{\circ}, 75.2^{\circ}$, and $79.3^{\circ}$ in nanoparticles. However, both rhombohedral and cubic structural nanoparticles have been reported in reference [10, 17, 23]. Well-defined diffraction peaks for (111), (200), (311), and (222) cubic Iron-doped NiO NPs $[10,17,22]$ were observed, which correspond to the standard spectrum (JCPDS, No.73-1519). At higher calcification temperatures, formed crystals get larger, which can be ascribed to thermally improved growth of crystals. The sizes of Iron doped $\mathrm{NiO}$ nanoparticles obtained from the diffraction ridges using the Scherrer equation are $5.6 \mathrm{~nm}$ and $9.6 \mathrm{~nm}$ and $11.6 \mathrm{~nm}$ for the sample calcined at $300^{\circ} \mathrm{C}, 350^{\circ} \mathrm{C}$, and $420^{\circ} \mathrm{C}$ respectively, the sizes of nanoparticles increase with an increase in calcification temperatures and, the crystalline volume increases as the calcification temperature increases. W-H analysis was performed to calculate the volume and fine diffraction contributions for the XRD line expansion. The very small diffraction values of all samples result in a close agreement between the estimated crystalline sizes from Scherrer's equation and the W-H analysis. The occurrence of vacancies and defects in composition Iron doped $\mathrm{NiO}$ nanoparticles can lead to subtle diffraction that leads to the widening of XRD peaks. From the Debye-Scherer equation, the average diameter of spherical particles can be easily calculated from

$$
D=\frac{k \lambda}{\beta \cos \cos \theta}
$$

where $\mathrm{D}$ represents the crystallite size, and $\mathrm{K}=0.89$ is the Scherrer constant and its associated with spherical particles and index (hkl) of the crystals. $\lambda=1.54^{\circ} \mathrm{A}$ wavelength of source, $\beta$ means the full width at half maximum (FWHM) of the peaks in radians. The average crystalline size increases from $4.83 \mathrm{~nm}$ to $14.5 \mathrm{~nm}$ as the calcination temperature increases and that is near previous studies $[22,24]$.

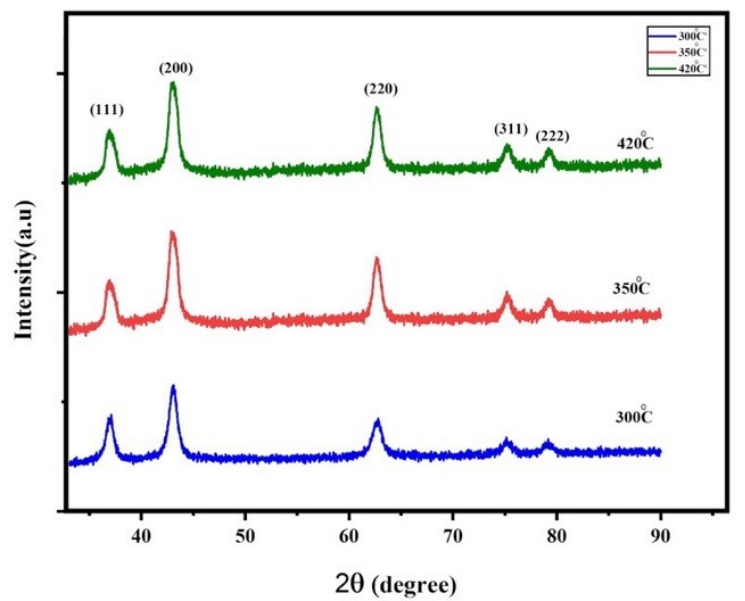

Figure 2: XRD structures of Iron doped NiO NPs samples at different calcination Temperatures

\subsection{SEM Analysis and EDX}

The particle size, shape, and morphology are identified using SEM micrographs. SEM images of the obtained Iron doped $\mathrm{NiO}$ NPs for the samples are shown in Fig.3. The SEM images show the morphology of the Iron doped $\mathrm{NiO}$ nanoparticles. It is observed that the shape of the particles is nearly spherical and Oval with non-homogeneous distribution, and they are in the range of $10 \mathrm{~nm}$ to $30 \mathrm{~nm}$ and that is close to the previous studies $[15,16,24,4]$. Particle size came out to be 4.6, 8.3, and $12.2 \mathrm{~nm}$ which means that particle size increases with the increase of the temperature. The particle size calculated from the SEM analysis seems to be quite similar to that measured from the XRD analysis of crystallite size. The EDX spectrum of Iron doped $\mathrm{NiO}$ nanoparticles is shown in Fig4. revealed the presence of Nickel, Oxygen, Carbon, and Iron is the only elementary species in samples.

\subsection{FTIR Analysis}

Figure 5 shows the FTIR spectra of Iron doped $\mathrm{NiO}$ particles samples calcined at 300,350 , and $420{ }^{\circ} \mathrm{C}$. To determine the chemical structure of the samples the spectra were observed over 
the frequency range of $590-4000 \mathrm{~cm}^{-1}$. The broad absorption band centered at $3450 \mathrm{~cm}^{-1}$ is assigned to $\mathrm{O}-\mathrm{H}$ stretching vibrations and the band at $1630 \mathrm{~cm}^{-1}$ is attributable to $\mathrm{H}-\mathrm{O}-\mathrm{H}$ bending vibration of water absorbed from the atmosphere when samples were prepared in the open air. Also, the absorption band in the region of $462-560 \mathrm{~cm}^{-1}$ is assigned to $\mathrm{Fe}-\mathrm{O}$ stretching vibration mode and the second broad absorption band in the region $410-474 \mathrm{~cm}$ ${ }^{-1}$ is assigned to $\mathrm{Ni}-\mathrm{O}$ stretching vibration mode. The broadness of the absorption band indicates that the $\mathrm{NiO}$ powders are nanocrystals and well crystallized. The intensity of $\mathrm{Ni}-\mathrm{O}$ and $\mathrm{F}$ - O stretching bands seen in Fig.5 are increasing as the calcination.
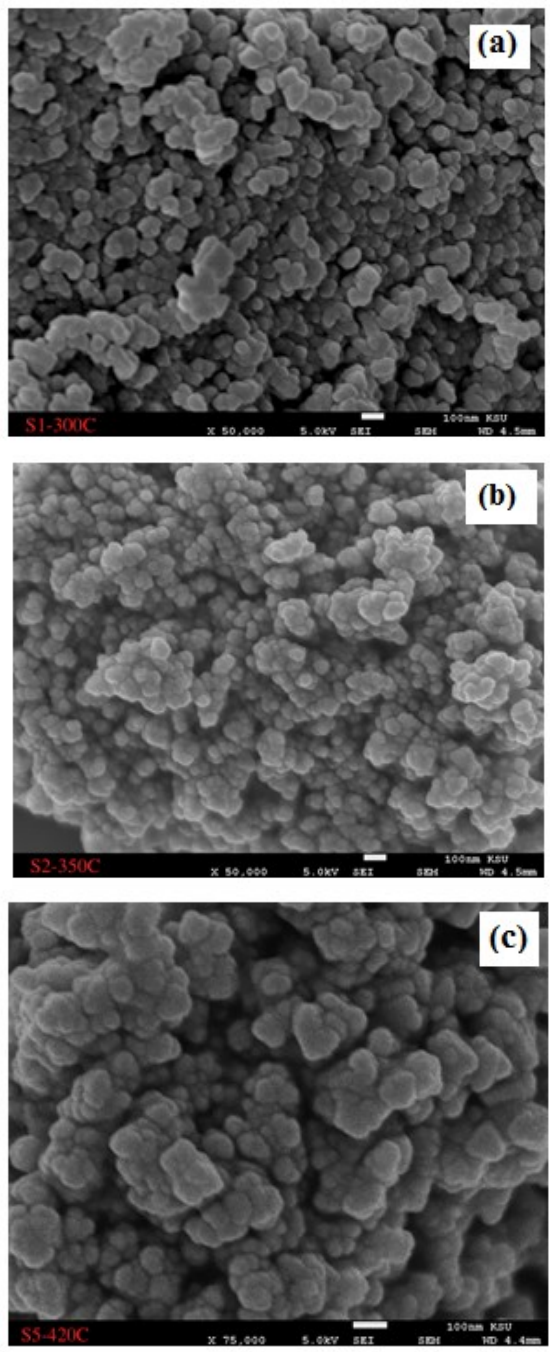

Figure 3: SEM images of Iron doped NiO NPs Calcined at (a)300, (b) 350, and (c) $420^{\circ} \mathrm{C}$.

\subsection{UV-Visible studies}

Figure 6 shows spectra for UV-visible absorption and $(\alpha h v)^{2}$ versus energy plot for Iron doped $\mathrm{NiO}$ nanoparticles samples. UV studies of absorption showed that a rise in calcination temperature results in a redshift in the absorption spectrum and a decrease in bandgap as a result of an increase in particle size. The peaks range in the ultraviolet spectrum showed between $(300-400 \mathrm{~nm})$ and that is close to the previous studies $[10,15]$. In general, the data show that the sample calcined at $300^{\circ} \mathrm{C}$ has a value of $307 \mathrm{~nm}$, and the value of $347 \mathrm{~nm}$ for the sample calcined at $350^{\circ} \mathrm{C}$, lastly the value
$436 \mathrm{~nm}$ for the sample calcined at $420^{\circ} \mathrm{C}$, the peaks mean the matter absorption of the spectrum and also work to stimulate the electrons. The best result of the Three samples is the sample calcined at $350^{\circ} \mathrm{C}$ with a bandgap value of $1.86 \mathrm{eV}$ and high absorption value which makes the bandgap a small value. At calcination temperatures, the properties of the material are enhanced.
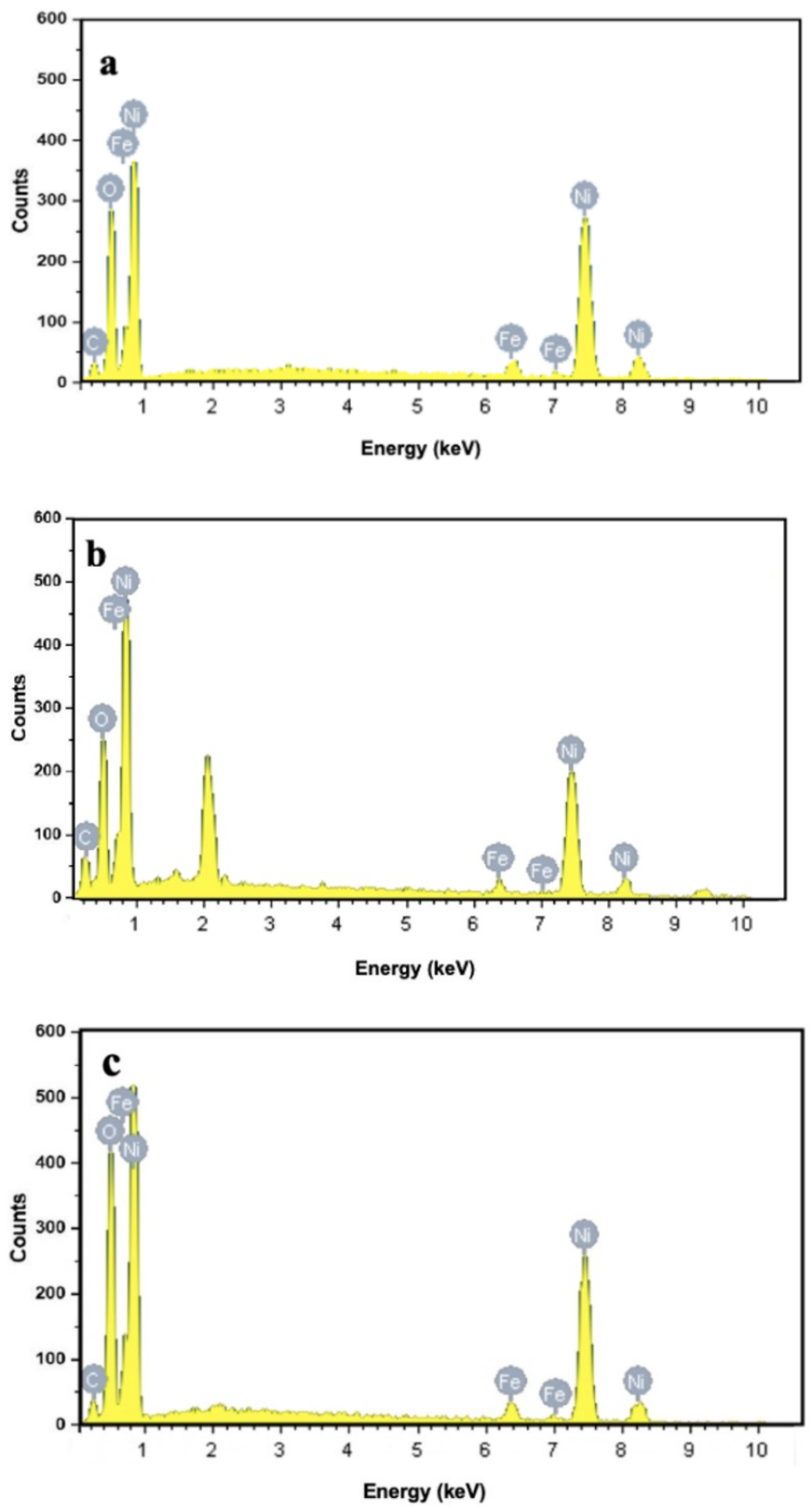

Figure 4: EDX spectra of Iron doped $\mathrm{NiO} N P s$ calcined at (a) $300^{\circ} \mathrm{C}$ (b) $350^{\circ} \mathrm{C}$, and (c) $420^{\circ} \mathrm{C}$

\section{Conclusions}

Nanostructured Iron doped $\mathrm{NiO}$ particles were prepared successfully utilizing nickel nitrate hexahydrate and ammonium carbonate via the chemical precipitation method. The results obtained from XRD is that the crystalline structure of nanoparticles has been improved due to the addition of $\mathrm{Fe}$ and calcined samples at different temperatures to be FCC, this 
observation is consistent with the previous studies. Furthermore, UV-visible absorption results have shown that a rise in the temperature of calcination causes a redshift in the absorption spectrum and a decrease in the bandgap due to an increase in the size of the particles. We can say calcination samples at high temperatures with a constant concentration of $\mathrm{Fe}$ are the main parameters of the appearance of a redshift in our results. Also, the particle size decreases with an increase in the dopant concentration of $\mathrm{Fe}$. Based on these systematic observations, it is concluded that calcined $\mathrm{NiO}$ doped with $5 \%$ Fe nanoparticles may have been an outstanding option for optoelectronic applications because of its desired structural and optical properties.

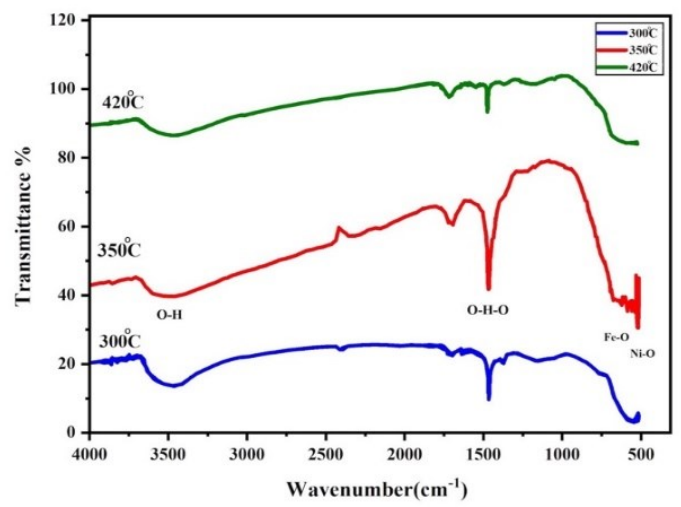

Figure 5: illustrates the FTIR spectra of the samples
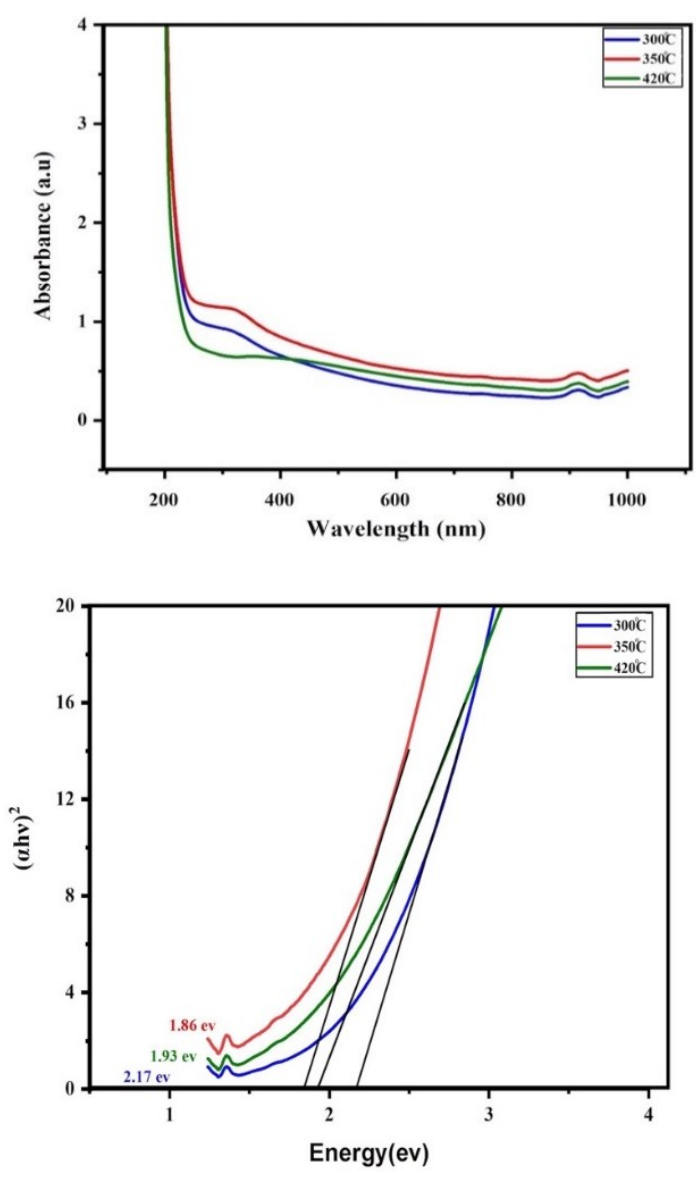

Figure.6 a- UV-Visible absorbance spectra. b- $(\alpha \mathrm{h} v)^{2}$ versus energy plot for $\mathrm{NiO}_{3}+\mathrm{FeO}_{3}$ nanoparticles.

\section{Acknowledgments}

This research was funded by the Deanship of Scientific Research at Princess Nourah bint Abdulrahman University, Riyadh, Kingdom of Saudi Arabia. In addition, we would like to remember Maha Almoneef, Fatima Alkalas, and Nourah Alwadei at the Department of Physics, College of Science at Princess Nourah Bint Abdulrahman University, for their contributions in this article

\section{References}

[1] H. Gleiter, "Nanocrystalline Materials," in: Bunk, W. G. J., ed., in Advanced Structural and Functional Materials, Springer Berlin Heidelberg, Berlin, Heidelberg: 1-37, 1991.

[2] J. Shi, X. Zhang, W. Baeyens, A.M. García-Campaña, "Recent developments in nanomaterial optical sensors," TrAC Trends in Analytical Chemistry, 23, 351-360, 2004, doi:10.1016/S0165-9936(04)00519-9.

[3] R. Palombari, "Influence of surface acceptor-donor couples on conductivity and other electrochemical properties of nonstoichiometric $\mathrm{NiO}$ at $200^{\circ} \mathrm{C}$," Journal of Electroanalytical Chemistry, 546, 23-28, 2003, doi:https://doi.org/10.1016/S0022-0728(03)00134-7.

[4] N.N.M. Zorkipli, N.H.M. Kaus, A.A. Mohamad, "Synthesis of NiO Nanoparticles through Sol-gel Method," Procedia Chemistry, 19, 626-631, 2016, doi:https://doi.org/10.1016/j.proche.2016.03.062.

[5] P. Mallick, C. S. Sahoo, N. C. Mishra, "Structural and optical characterization of $\mathrm{NiO}$ nanoparticles synthesized by sol-gel route," in: Bose, S. M. and Tripathy, S. K., eds., in Functional Materials, 229-232, 2012, doi:10.1063/1.4736893.

[6] P. Jeevanandam, V.R.R. Pulimi, "Synthesis of nanocrystalline NiO by solgel and homogeneous precipitation methods," Indian Journal of Chemistry Section A Inorganic, Physical, Theoretical and Analytical Chemistry, 51, 586-590, 2012.

[7] M. Alagiri, S. Ponnusamy, C. Muthamizhchelvan, "Synthesis and characterization of $\mathrm{NiO}$ nanoparticles by sol-gel method," Journal of Materials Science-Materials in Electronics - J MATER SCI-MATER ELECTRON, 23, 2012, doi:10.1007/s10854-011-0479-6.

[8] P. Mallick, C. Rath, R. Biswal, N.C. Mishra, "Structural and magnetic properties of Fe doped NiO," Indian Journal of Physics, 83, 517-523, 2009, doi:10.1007/s12648-009-0012-4.

[9] S. Takami, R. Hayakawa, Y. Wakayama, T. Chikyow, "Continuous hydrothermal synthesis of nickel oxide nanoplates and their use as nanoinks for p-type channel material in a bottom-gate field-effect transistor," Nanotechnology, 21, 134009, 2010, doi:10.1088/0957-4484/21/13/134009.

[10] W. Duan, S. Lu, Z. Wu, Y. Wang, "Size Effects on Properties of NiO Nanoparticles Grown in Alkalisalts," The Journal of Physical Chemistry C, 116, 26043-26051, 2012, doi:10.1021/jp308073c.

[11] V. Biju, M. Khadar, "Analysis of AC Electrical Properties of Nanocrystalline Nickel Oxide," Materials Science and Engineering: A, 304, 814-817, 2001, doi:10.1016/S0921-5093(00)01581-1.

[12] S. Chakrabarty, K. Chatterjee, "Synthesis and Characterization of NanoDimensional Nickelous Oxide (NiO) Semiconductor," J. Phys. Sci., 13, 2009

[13] M.A. Marselin, N. Jaya, "Synthesis and characterization of Pure and Cobaltdoped NiO Nanoparticles," 2015.

[14] M. rifaya, T. Thirugnanasambandan, M. Alagar, "Chemical Capping Synthesis of Nickel Oxide Nanoparticles and their Characterizations Studies," Nanoscience and Nanotechnology, 2, 2012, doi:10.5923/j.nn.20120205.01.

[15] P. Sheena, P. K P, A. Nedumkallel, B. Sabu, T. Varghese, M. Asmabi, "EFFECT OF CALCINATION TEMPERATURE ON THE STRUCTURAL AND OPTICAL PROPERTIES OF NICKEL OXIDE NANOPARTICLES," 5, 2014

[16] K.N. Patel, M.P. Deshpande, V.P. Gujarati, S. Pandya, V. Sathe, S.H. Chaki, "Structural and optical analysis of Fe doped $\mathrm{NiO}$ nanoparticles synthesized by chemical precipitation route," Materials Research Bulletin, 106, 187-196, 2018, doi:10.1016/j.materresbull.2018.06.003.

[17] P.M. Ponnusamy, S. Agilan, N. Muthukumarasamy, T.S. Senthil, G. Rajesh, M.R. Venkatraman, D. Velauthapillai, "Structural, optical and magnetic properties of undoped $\mathrm{NiO}$ and $\mathrm{Fe}$-doped $\mathrm{NiO}$ nanoparticles synthesized by wet-chemical process," Materials Characterization, 114(C), 166-171, 2016, doi:10.1016/j.matchar.2016.02.020.

[18] K. R, J. G, A.A. Alphonse, A. Raj, "Structural and Magnetic Properties of 1425 
$\mathrm{NiO}$ and Fe-doped $\mathrm{NiO}$ Nanoparticles Synthesized by Chemical Coprecipitation Method," Materials Today: Proceedings, 3, 1370-1377, 2016, doi:10.1016/j.matpr.2016.04.017.

[19] H. Abbas, K. Nadeem, A. Hassan, S. Rahman, H. Krenn, "Enhanced photocatalytic Activity of Ferromagnetic Fe-doped NiO nanoparticles," Optik, 202, 163637, 2020, doi:https://doi.org/10.1016/j.ijleo.2019.163637.

[20] R. Pradeep, A.C. Gandhi, Y. Tejabhiram, I.K.M.M. Sahib, Y. Shimura, L. Karmakar, D. Das, S.Y. Wu, Y. Hayakawa, "Magnetic anomalies in Fedoped $\{\mathrm{NiO}\}$ nanoparticle," Materials Research Express, 4(9), 96103, 2017, doi:10.1088/2053-1591/aa7f9b.

[21] H. Muthusamy, N. Suriyanarayanan, S. Prabahar, "Nanoscale synthesis and optical features of nickel nanoparticles," Optik - International Journal for Light and Electron Optics, 125, 1962-1966, 2014, doi:10.1016/j.ijleo.2013.09.069.

[22] K. Krishnan, K. Selvan, M. Kanagaraj, S. Arumugam, N. Jaya, "Particle size effect on the magnetic properties of $\mathrm{NiO}$ nanoparticles prepared by a precipitation method," Journal of Alloys and Compounds - J ALLOYS COMPOUNDS, 509, 181-184, 2011, doi:10.1016/j.jallcom.2010.09.033.

[23] Z.M. Khoshhesab, M. Sarfaraz, "Preparation and Characterization of NiO Nanoparticles by Chemical Precipitation Method," Synthesis and Reactivity in Inorganic, Metal-Organic, and Nano-Metal Chemistry, 40(9), 700-703, 2010, doi:10.1080/15533174.2010.509710.

[24] M. Bonomo, "Synthesis and characterization of $\mathrm{NiO}$ nanostructures: a review," Journal of Nanoparticle Research, 20, 2018, doi:10.1007/s11051018-4327-y. 